\title{
Items for consideration in a reporting guideline for mediation analyses: a Delphi study
}

$\begin{array}{ll}\text { Aidan G Cashina,b } & \text { Email: a.cashin@neura.edu.au } \\ \text { James H McAuleya,c } & \text { Email: j.mcauley@neura.edu.au } \\ \text { Sarah E Lambd,e } & \text { Email: sarah.lamb@ndorms.ox.ac.uk } \\ \text { Sally Hopewelld } & \text { Email: sally.hopewell@csm.ox.ac.uk } \\ \text { Steven J Kamperf,g } & \text { Email: steven.kamper@sydney.edu.au } \\ \text { Christopher M Williamsg,h } & \text { Email: christopher.m.williams@hnehealth.nsw.gov.au } \\ \text { Nicholas Henschkei } & \text { Email: nicholas.henschke@sydney.edu.au } \\ \text { Hopin Leed,h* } & \text { Email: hopin.lee@ndorms.ox.ac.uk }\end{array}$

aNeuroscience Research Australia, Sydney, Australia

bPrince of Wales Clinical School, Faculty of Medicine, University of New South Wales, Sydney,

Australia

cSchool of Medical Sciences, Faculty of Medicine, University of New South Wales, Sydney, Australia dOxford Clinical Trials Research Unit and Centre for Statistics in Medicine, Nuffield Department of Orthopaedics Rheumatology and Musculoskeletal Sciences (NDORMS), University of Oxford,

Oxford, UK

eInstitute of Health Research, University of Exeter Medical School, Exeter, UK

fInstitute for Musculoskeletal Health, Faculty of Medicine and Health, University of Sydney, Sydney,

Australia

gCentre for Pain, Health and Lifestyle, Newcastle, Australia

hSchool of Medicine and Public Health, University of Newcastle, Newcastle, Australia

iSchool of Public Health, University of Sydney, Sydney, Australia

\section{*Corresponding Author:}

Dr Hopin Lee

Botnar Research Centre

Nuffield Department of Orthopaedics Rheumatology and Musculoskeletal Sciences, University of

Oxford, Windmill Road, Headington, Oxford, UK OX3 7LD

Tel: +44018652 26493

Email: hopin.lee@ndorms.ox.ac.uk

Pages: 18

Word count: 2574 (up to 3500)

Figures and tables: 2 figure, 2 tables ( 1 online supplementary appendix table) 


\section{SUMMARY BOX}

\section{What is already known about this subject}

- Mediation analysis is a widely used quantitative method for investigating the mechanisms of interventions and exposures in randomised controlled trials and observational studies.

- Reporting of studies that use mediation analysis is often heterogeneous and incomplete.

\section{What are the new findings?}

- Nineteen international experts reached consensus on 34 items that should be reported in studies that use mediation analysis. These experts also contributed 60 qualitative comments to help refine and prioritise items for the final reporting guideline.

\section{How might it impact on research practice in the foreseeable future?}

- The level of agreement and importance of these 34 items, in addition to the experts' comments will inform a consensus meeting to confirm the final list of reporting items that will be included in a reporting guideline for studies using mediation analysis.

- Complete and transparent reporting of studies that use mediation analysis can facilitate clinical application, reproducibility, and evidence synthesis. 


\section{ABSTRACT}

\section{Objective}

Mediation analysis is a widely used quantitative method for investigating how interventions and exposures in randomised controlled trials and observational studies have an effect on healthcare outcomes. This study aimed to assess the importance of items that should be considered in a consensus meeting aimed at developing a guideline for reporting mediation analyses.

\section{Study Design and Setting}

A Delphi panel of international experts were asked to rate the importance of a list of items for inclusion in a guideline for reporting mediation analyses. Thresholds for disagreement and consensus on importance for inclusion were specified a priori. We used the Research ANd

Development/University of California Los Angeles appropriateness method to quantitatively assess the importance for inclusion and panel agreement.

\section{Results}

Nineteen expert panellists (10 female) from seven countries agreed to participate. All panellists contributed to all three rounds conducted between 10/06/2019 and 06/11/2019. The panel reached consensus on 34 unique reporting items for study design, analytic procedures and effect estimates, with 3 items rated 'optional'. Panellists added one extra item and provided 60 qualitative comments for item refinement and prioritisation.

\section{Conclusion}

This Delphi study used a rigorous consensus process to reach consensus on 34 reporting items for studies that use mediation analysis. These results will inform a consensus meeting that will consolidate a core set of recommended items for reporting mediation analyses.

\section{Key words}

Mediation analysis, mechanisms, reporting guideline, Delphi 


\section{INTRODUCTION}

Health exposures and interventions have their effects on outcomes through causal mechanisms.[1] Mediation analyses of randomised controlled trials and observational studies have been used to understand the mechanisms by which an intervention or exposure has an effect on a given outcome.[2,3] Mediation analysis is an analytical method that is used to separate the effect of an exposure or intervention into an 'indirect effect' which works through the mechanism(s) of interest, and a 'direct effect' which works through all other mechanisms. The results from mediation analyses are used to develop and optimise interventions, and to inform the implementation of policy and clinical care.[4-6] Research into understanding causal mechanisms has been endorsed by the UK Medical Research Council (MRC)[1] and National Institute for Health Research (NIHR) through their Efficacy and Mechanism Evaluation Programme[7] and is also recommended by other national funding bodies.

Although the application of mediation analysis to randomised trials and observational studies is increasing exponentially (Figure 1),[8] recent systematic reviews have identified inadequate reporting of mediation analyses.[9-16] Vo et al (2020) found that $96 \%$ of randomised controlled trials that use mediation did not report a sample size calculation and $70 \%$ did not report any underlying assumptions of mediation analyses.[16] There are no specific reporting guidelines for studies that use mediation analysis; and generic guidelines such as the Consolidated Standards of Reporting Trials (CONSORT) [17] and the Strengthening the Reporting of Observational Studies in Epidemiology (STROBE)[18] do not cover the additional aspects of study design, analysis, and effects that should be reported in a mediation analysis. Numerous papers have highlighted the need for a specific reporting guideline for mediation analyses.[9,14-16]

In 2017 we formed an international working group to develop A Guideline for Reporting Mediation Analysis (AGReMA).[19] The AGReMA project methods are in accordance with the Guidance for Developers of Health Research Reporting Guidelines by Moher et al (2010).[20] After the completion of reviews to assess the extent of reporting inadequacies, we conducted a Delphi study to reach expert consensus on items that should be considered in a consensus meeting that will consolidate a core set of recommended items for reporting mediation analyses.

\section{METHODS}

A Delphi study is a structured method for achieving consensus among a panel of experts on a given question or topic.[21] The process involved developing an initial exhaustive list of reporting items from previous reviews and consultation with experts, followed by a series of online surveys to: (1) assess the level of agreement on the initial list of reporting items; (2) elicit additional items and 
clarification on items to refine the initial list; and (3) identify which items are considered critically important in reporting mediation studies. We preregistered the protocol prior to data collection on 21 May 2019 on the Open Science Framework, (https://osf.io/xwka6). The University of New South Wales Human Research Ethics Advisory Panel granted ethical approval (HC16599).

\section{Selection of preliminary items}

We generated an exhaustive preliminary list of 33 items to be considered in the first round of the Delphi based on a scoping review of existing methods and reporting guidance documents for mediation analyses, and from the findings of our recent overview of systematic reviews.[15] In addition, we examined items from the CONSORT and STROBE checklist $[17,18]$ to identify potential reporting items that could be adapted for mediation studies.

\section{Selection of experts}

We compiled a list of experts who had experience in the development and application of mediation analysis. Experts included those who had published original research papers involving mediation analysis or systematic reviews of mediation studies; or a methodological/statistical paper on mediation analysis; or a textbook on mediation analysis. Experts were identified through a variety of sources including an overview[15] and a scoping review of the literature, and through informal discussions with key stakeholders. Recruitment was an iterative process, with the final list of experts for the Delphi panel determined by the AGReMA working group. The panel size for the Delphi consensus methodology[22] is best qualified in terms of its 'expertness' rather than its size,[23] differing to surveys which require larger sample sizes for statistical power. We, like most other Delphi studies [24,25], used the definition by Fink et al. (1984) that an expert "should qualify for selection because they are representative of their profession, have power to implement the findings, or because they are not likely to be challenged as experts in the field".[26]

\section{Delphi procedure}

The Delphi procedure involves a series of 'rounds', where panellists independently and anonymously contribute and rank items until pre-defined consensus is reached. A central component of the Delphi procedure is the provision of summary feedback to panellists after each round to encourage the reflection on judgements for subsequent rounds to assist transforming individual opinion into group consensus.[21] The Delphi technique enables the anonymous contribution of experts across geographic locations while reducing the limitations imposed by group dynamics such as the dominance of a few panel members.[21,27,28] We collaborated with CLINVIVO (www.clinvivo.com), an independent company that designs and facilitates web-based Delphi studies. CLINVIVO developed a bespoke electronic data capture program and co-ordinated the data collection and analysis for each Delphi round. 
The first Delphi round started on 10/06/2019 and the third (final) round concluded on 06/11/2019. Each round took 3 to 5 weeks. Panellists were sent three reminders to ensure an adequate response rate.

Round one

All panellists were sent a link that included a description of the project, demographic questionnaire, and the preliminary list of reporting items for consideration. Panellists rated the importance of each item on a 9-point Likert scale (1, 'not important', to 9, 'critically important') and scored their confidence in their ratings (1, 'not confident', to 9, 'very confident'). Panellists also provided free-text suggestions on item wording, where applicable, and proposed additional items for consideration in the subsequent round.

\section{Round two}

The link to round two included a summary of results from round one (mean scores and standard deviations, median scores and inter-percentile ranges (IPR), histograms and descriptive labels of importance and agreement level, anonymised qualitative comments), together with the panellists' own score of importance for each item.[29] Newly nominated items and suggested re-wording of items from round one were also presented. Panellists re-rated the importance of each item in the light of the round one results and re-scored their confidence in their ratings on a 9-point Likert Scale (1, 'not confident', to 9, 'very confident'). Panellists were informed that items scored for importance $\leq 3$ would be excluded, and items scored $\geq 7$ would be considered critically important for the draft guideline to be discussed at the consensus meeting.

\section{Round three}

The link to round three included a summary of results from round two (mean/medians and standard deviations/IPRs, histograms, descriptive labels of importance and agreement level, anonymised qualitative comments), together with the panellist's own scores on importance. Panellists were informed which items had reached a median importance score $\geq 7$ to be included and which items reached a median score $\leq 3$ to be excluded. Panellists categorised the remaining items for which consensus had not been reached (median score 4-6 or where disagreement exists - see analysis below) as either: 1) 'Include as optional' or 2) 'Exclude'. Panellist also scored their confidence in their ratings on a 9-point Likert Scale (1, 'not confident', to 9, 'very confident').

\section{Data analysis}

We used descriptive statistics to summarise demographic data from included panellists. We coded and thematically grouped the free text comments from round one and two to identify the key issues and 
common themes. We used the Research ANd Development/University of California Los Angeles (RAND/UCLA) appropriateness method to analyse the scores from each round. We modified this approach by asking panellists to rate 'importance' rather than 'appropriateness'. The RAND/UCLA appropriateness method considers the median panel rating and dispersion of each panel rating to provide an index of importance and agreement.[22] This involves calculating the median score, the IPR (30th and 70th) and the inter-percentile range adjusted for symmetry (IPRAS) for each item being rated. We considered agreement to be present when the IPR was equal to or less than the IPRAS and disagreement to be present when the IPR was greater than the IPRAS.[22] For the analysis of the round one and two, we considered the RAND/UCLA definitions for consensus on items to be considered for the reporting guideline as [22]:

- 'Include': panel median of 7-9 for importance, without disagreement

- 'Uncertain': panel median of 4-6 for importance, or any median with disagreement

- 'Exclude': panel median of 1-3 for importance, without disagreement

For the analysis of round three, we considered consensus for items to be considered for the reporting guideline as [24]:

- 'Include as optional': panel majority as include

- 'Exclude': panel majority as exclude

\section{RESULTS}

\section{Demographics of participants}

Of the 40 invited experts, 19 consented and agreed to participate. Table 1 describes the panel demographics.

\section{*Table 1 here*}

\section{Round one}

In round one, the 19 panellists rated 33 items of which 30 achieved consensus (Figure 2) as 'important items' (median score $\geq 7$ ), three achieved consensus of 'uncertain importance' (median score 4-6) and zero were considered 'not important' items (median score $\leq 3$ ) (Table 2). The IPRAS was greater than the IPR for all item scores indicating no disagreement between experts in round one. The panellists provided 37 qualitative comments suggesting clarifications for 10 items and the addition of one item (Appendix, Table 1).

\section{*Table 2 here*}

\section{Round two}

All 19 panellists completed round two. Panellists rated a total of 14 items, including 10 items adapted from round one to improve clarity (items 1, 8, 7, 9, 12, 14, 18, 19, 24, 26, 31 in Table 2), three items 
which were rated of 'uncertain importance' (items 7, 17, 30 in Table 2) and one newly suggested item (item 34 in Table 2). Of these 14 items, 11 achieved consensus as 'important' (median score $\geq 7$ ) (items 1, 8, 9, 12, 14, 18, 19, 24, 26, 31, 34 in Table 2), three remained 'uncertain' (median score 4-6) (items 7, 17, 30 in Table 2) and zero were considered 'not important' items (median score $\leq 3$ ). The IPRAS was greater than the IPR for all item scores indicating no disagreement between experts in round two. The panellists provided 14 qualitative comments on 9 items (Appendix, Table 1). These comments provided feedback on the revised wording, the additional item from round one, and the three 'uncertain' items. The experts suggested that the three 'uncertain' items (items 7, 17, 30, Table 2) were not specific or relevant to mediation studies and should be considered 'optional' items.

\section{Round three}

All 19 panellists completed round three. Panellists reached consensus to include the three remaining items (items 7, 17, 30) as 'optional' items. The panellists provided 9 additional qualitative comments supporting the 'optional' consideration for the three items (items 7, 17, 30) (Appendix, Table 1).

In summary, round one reached consensus to include 20 items, round two reached consensus to include an additional 11 items, and round three reached consensus to include the three final items as 'optional' (Figure 2). No item from the preliminary list reached consensus for exclusion. The final list included 34 items which achieved consensus to be considered for AGReMA.

\section{Summary of free-text response}

The panellists provided 60 item-specific and general comments during the three Delphi rounds (Appendix, Table 1). The comments helped revise 13 (39\%) of the preliminary Delphi items, and introduced one additional item. Panellists comments also raised concern on the number of items and the degree of detail; "some of these questions concern overlapping topics, so I would simplify them". Further, some panellists described the need for the guideline to be more specific to mediation; "I think some of your entries are not specific to mediation analysis but general for any scientific papers"; and the relevance of the guideline for all mediation publication types; "I think [the] reporting guideline also need to take into account whether the entire paper is on mediation, or whether this is just a secondary analysis with the primary analysis (in the same paper) being the analysis of total effects". All item-specific and general comments were circulated to panellists in each subsequent round.

\section{DISCUSSION}

A group of international experts in mediation analysis reached consensus on a preliminary list of 34 items that should be considered in the next stage of the AGReMA project, a consensus and guideline development meeting. The Delphi method is an important step that engages key stakeholders in the 
process of developing a reporting guideline.[20] We included a representative panel of experts who achieved a high level of agreement $(\geq 7 / 9)$ and confidence $(\geq 7 / 9)$ in item ratings. In each round of the Delphi, there was no evidence of disagreement between panellists based on the RAND/UCLA appropriateness method. This evidence generated from a group of international experts contributes to the growing literature of reporting practices in mediation analysis and will guide the development of AGReMA.

The panellists' item-specific and general comments provided valuable insights for item refinement and prioritisation. The comments also raised concerns to be further addressed at the consensus meeting, including the need for a concise, mediation specific guideline that is suitable for all mediation analysis publication types. The recent Guidance for Reporting Involvement of Patients and the Public (GRIPP2) reporting guideline produced two versions of their reporting checklist: a long form for studies where patient and public involved is the primary focus, and a short form for studies where it is a secondary or tertiary focus.[30] This format could also be adopted in AGReMA as mediation analyses of randomised trials and observational studies are also reported as primary and secondary publications.

Although the preliminary list contained an exhaustive list of reporting items, all items eventually reached consensus for inclusion. The majority of items were related to study methods $(25 / 34,74 \%)$. This is in keeping with the function of reporting guidelines to describe study features that influence the risk of bias.[31] Our current list of 34 items is larger than CONSORT (25 items) and STROBE (22 items). In this Delphi, we purposefully split broad concepts into separate items. In the consensus meeting we may merge related items to reduce the number of items to enhance useability.

\section{Strengths and limitations}

We prospectively registered the protocol prior to data collection and used robust methodology to conduct this Delphi study. We used a priori thresholds of disagreement and consensus. We used the RAND/UCLA method to measure panel disagreement and to establish clear boundaries of 'importance' for inclusion. The Delphi rounds and data collection were externally conducted by CLINVIVO to avoid influence from the AGReMA working group.[32] Finally, we obtained 100\% follow-up and completion rates at all rounds.

There are some limitations to our study. The results from this study are only as externally valid as the representation of the expert panel. We attempted to include a diverse, international panel of experts who represented key stakeholders. Nineteen (49\%) of the 40 invited experts agreed to participate in this study which is consistent with other Delphi recruitment rates.[25,33] However, we cannot be sure that our sample accurately represents the experts who chose not to participate. The definition of an 
expert itself has been debated. To safeguard the validity of our findings, we used systematic methodology to identify experts who meet the definition suggested by Fink et al. (1984).[26]

\section{CONCLUSION}

Based on a Delphi process, a preliminary list of 34 reporting items for studies that use mediation analysis were identified. These findings will inform a consensus meeting to develop a guideline for reporting mediation studies that is relevant across disciplines, study designs and publication types.

\section{DECLARATIONS}

\section{List of abbreviations}

None

\section{Ethics approval and consent to participate}

Ethics approval was obtained from the University of New South Wales Human Research Ethics Advisory Panel D: Biomedical, approval number HC16599.

\section{Submission declaration and verification}

This article has not been previously published

\section{Availability of data and materials}

The dataset used and analysed during this study is available from the corresponding author on reasonable request.

\section{Funding}

This work was supported by project funding from the Berkeley Initiative for Transparency in the Social Sciences, a program of the Center for Effective Global Action (CEGA), with support from the Laura and John Arnold Foundation. The funding body did not contribute to the design of the study, the collection, analysis and interpretation of data and in writing the manuscript.

\section{Competing interests}

AC is supported by the University of New South Wales Prince of Wales Clinical School Postgraduate Research Scholarship and a NeuRA PhD Candidature Supplementary Scholarship, and is a Catalyst for the Berkeley Initiative for Transparency in the Social Sciences. HL is funded by the National Health and Medical Research Council (APP1126767); National Institute for Health Research (NIHR) Collaboration for Leadership in Applied Health Research and Care Oxford at Oxford Health NHS 
Foundation Trust; received project funding from the Berkeley Initiative for Transparency in the Social Sciences, a program of the Center for Effective Global Action (CEGA), with support from the Laura and John Arnold Foundation; and is a Catalyst for the Berkeley Initiative for Transparency in the Social Sciences. SK is funded by the National Health and Medical Research Council (APP1127932).

\section{Author contributions}

$\mathrm{AC}, \mathrm{HL}$ and JM conceived the idea for the project and prepared the initial list of reporting items. All authors contributed to the project design and protocol development. AC and HL collected and analysed data with CLINVIVO. AC wrote the first draft of the manuscript. All authors provided substantive feedback on the manuscript and have read and approved the final version.

\section{Acknowledgments}

We thank Dr Rob Froud and the CLINVIVO team for providing their expertise and guidance in conducting and analysing this Delphi study. We are also grateful to the Delphi participants for their substantive engagement and feedback. 


\section{REFERENCES}

1 Moore GF, Audrey S, Barker M, et al. Process evaluation of complex interventions: Medical Research Council guidance. Br Med J 2015;350:h1258. doi:10.1136/bmj.h1258

2 Lee $\mathrm{H}$, Herbert RD, Lamb SE, et al. Investigating causal mechanisms in randomised controlled trials. Trials 2019;20:524. doi:10.1186/s13063-019-3593-Z

3 Lange T, Hansen KW, Sørensen R, et al. Applied mediation analyses: a review and tutorial. Epidemiol Health 2017;39:e2017035. doi:10.4178/epih.e2017035

$4 \quad$ VanderWeele T. Explanation in Causal Inference. Oxford: : Oxford University Press 2015. doi:10.15713/ins.mmj.3

$5 \quad$ Keele L, Tingley D, Yamamoto T. Identifying mechanisms behind policy interventions via causal mediation analysis. J Policy Anal Manag 2015;34:937-63. doi:10.1002/pam.21853 Lee H, Lamb SE. Advancing Physical Therapist Interventions by Investigating Causal Mechanisms. Phys Ther 2017;97:1119-21. doi:10.1093/ptj/pzx095

7 Efficacy and Mechanism Evaluation | NIHR. https://www.nihr.ac.uk/explore-nihr/fundingprogrammes/efficacy-and-mechanism-evaluation.htm (accessed 28 Jan 2020).

8 Nguyen TQ, Schmid I, Stuart EA. Clarifying causal mediation analysis for the applied researcher: Defining effects based on what we want to learn. Published Online First: 2019.http://arxiv.org/abs/1904.08515

9 Liu S, Ulbricht CM, Chrysanthopoulou SA, et al. Implementation and reporting of causal mediation analysis in 2015: a systematic review in epidemiological studies. BMC Res Notes 2016;9. doi:10.1186/s13104-016-2163-7

10 Gelfand LA, Mensinger JL, Tenhave T. Mediation Analysis: A Retrospective Snapshot of Practice and More Recent Directions NIH Public Access. J Gen Psychol 2009;136:15376.http://europepmc.org/backend/ptpmcrender.fcgi?accid=PMC2670477\&blobtype=pdf (accessed 25 Jul 2018).

11 Mansell G, Kamper SJ, Kent P. Why and how back pain interventions work: What can we do to find out? Best Pract Res Clin Rheumatol 2013;27:685-97. doi:10.1016/j.berh.2013.10.001

12 Hertzog M. Trends in Mediation Analysis in Nursing Research: Improving Current Practice. West J Nurs Res 2018;40:907-30. doi:10.1177/0193945916687782

13 Wood RE, Goodman JS, Beckmann N, et al. Mediation testing in management research: A review and proposals. Organ Res Methods 2008;11:270-95. doi:10.1177/1094428106297811

14 Lapointe-Shaw L, Bouck Z, Howell NA, et al. Mediation analysis with a time-to-event outcome: a review of use and reporting in healthcare research. BMC Med Res Methodol 2018;18:118. doi:10.1186/s12874-018-0578-7

15 Cashin AG, Lee H, Lamb SE, et al. An overview of systematic reviews found suboptimal reporting and methodological limitations of mediation studies investigating causal mechanisms. J Clin Epidemiol Published Online First: 20 March 2019. doi:10.1016/J.JCLINEPI.2019.03.005

16 Vo T, Superchi C, Boutron I, et al. The conduct and reporting of mediation analysis in recently published randomized controlled trials: results from a methodological systematic review. $J$ Clin Epidemiol 2020;117:78-88. doi:10.1016/j.jclinepi.2019.10.001

17 Schulz KF, Altman DG, Moher D. CONSORT 2010 Statement: Updated guidelines for reporting parallel group randomised trials. BMC Med 2010;8:18. doi:10.1186/1741-7015-8-18

18 Elm E von, Altman DG, Egger M, et al. Strengthening the reporting of observational studies in epidemiology (STROBE) statement: guidelines for reporting observational studies. BMJ 2007;335:806-8. doi:10.1136/bmj.39335.541782.AD

19 Cashin AG, McAuley JH, Lamb SE, et al. Development of A Guideline for Reporting Mediation Analyses (AGReMA). BMC Med Res Methodol 2020;20:19. doi:10.1186/s12874020-0915-5

20 Moher D, Schulz KF, Simera I, et al. Guidance for developers of health research reporting guidelines. PLoS Med. 2010;7:e1000217. doi:10.1371/journal.pmed.1000217

21 Jones J, Hunter D. Consensus methods for medical and health services research. BMJ 1995;311:376-80. doi:10.1136/BMJ.311.7001.376

22 Fitch K, Bernstein SJ, Aguilar MD, et al. The RAND/UCLA Appropriateness Method User's 
Manual Library of Congress Cataloging-in-Publication Data. Published Online First: 2001. doi:10.1180/minmag.2012.076.8.57

23 Froud R, Amundsen P, Bartys S, et al. Opportunities and challenges around adapting supported employment interventions for people with chronic low back pain: modified nominal group technique. Disabil Rehabil 2020.

24 Froud R, Eldridge S, Kovacs F, et al. Reporting outcomes of back pain trials: A modified Delphi study. Eur J Pain 2011;15:1068-74. doi:10.1016/j.ejpain.2011.04.015

25 Slade SC, Dionne CE, Underwood M, et al. Consensus on Exercise Reporting Template (CERT): Modified Delphi Study.

26 Fink A, Kosecoff J, Chassin M, et al. Consensus methods: characteristics and guidelines for use. Am J Public Health 1984;74:979-83. doi:10.2105/ajph.74.9.979

27 Boulkedid R, Abdoul H, Loustau M, et al. Using and Reporting the Delphi Method for Selecting Healthcare Quality Indicators: A Systematic Review. PLoS One 2011;6:e20476. doi:10.1371/journal.pone.0020476

28 Sinha IP, Smyth RL, Williamson PR. Using the Delphi technique to determine which outcomes to measure in clinical trials: Recommendations for the future based on a systematic review of existing studies. PLoS Med 2011;8:e1000393. doi:10.1371/journal.pmed.1000393

29 Murphy MK, Sanderson C, Black NA, et al. Consensus development methods, and their use in clinical guideline development. 1998. www.hta.ac.uk/htacd.htm (accessed 27 Nov 2019).

30 Staniszewska S, Brett J, Simera I, et al. GRIPP2 reporting checklists: Tools to improve reporting of patient and public involvement in research. BMJ 2017;358. doi:10.1136/bmj.j3453

31 Simera I, Moher D, Hirst A, et al. Transparent and accurate reporting increases reliability, utility, and impact of your research: Reporting guidelines and the EQUATOR Network. BMC Med 2010;8:24. doi:10.1186/1741-7015-8-24

32 Diamond IR, Grant RC, Feldman BM, et al. Defining consensus: A systematic review recommends methodologic criteria for reporting of Delphi studies. J Clin Epidemiol 2014;67:401-9. doi:10.1016/j.jclinepi.2013.12.002

33 Pinnock H, Epiphaniou E, Sheikh A, et al. Developing standards for reporting implementation studies of complex interventions ( StaRI ): a systematic review and e-Delphi Developing standards for reporting implementation studies of complex interventions ( StaRI ): a systematic review and e-Delphi. Implement Sci 2015;10. doi:10.1186/s13012-015-0235-z 


\section{FIGURES}
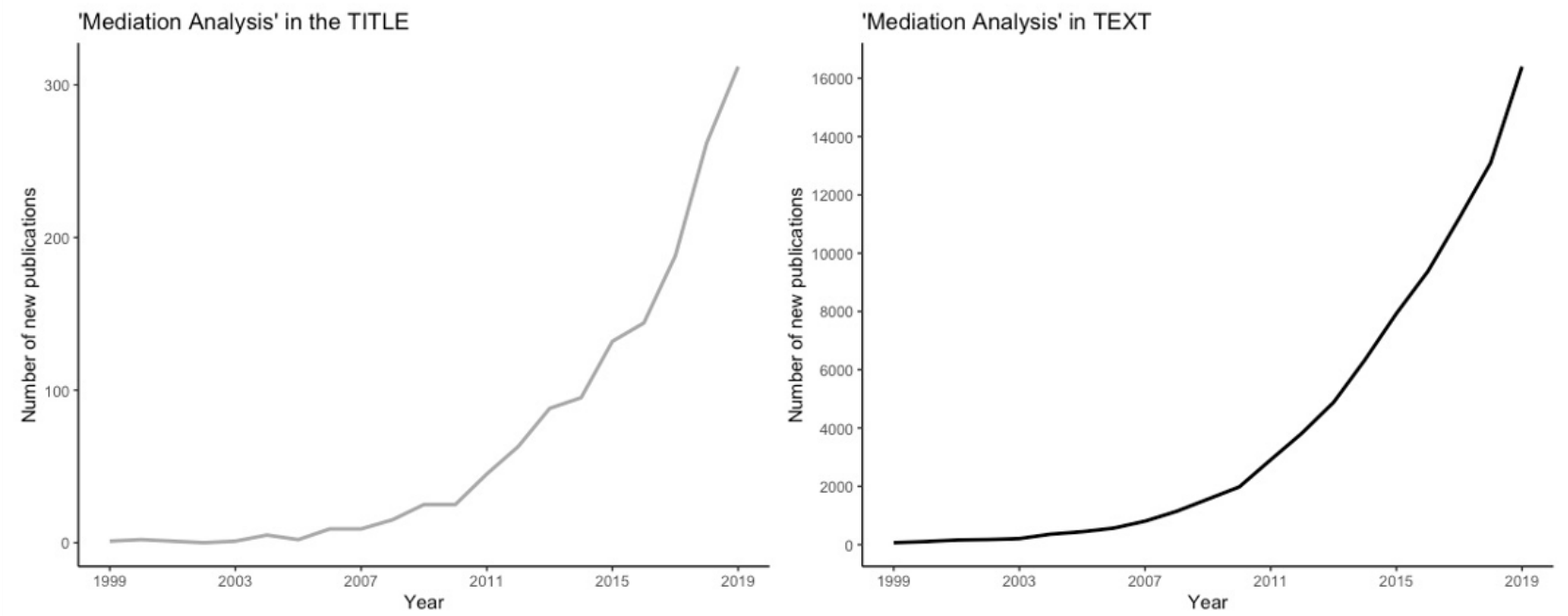

Figure 1. An increasing trend in the publication of mediation analysis research. The figure displays publication counts from two searches in Google Scholar for articles (excluding patents and citations) with "mediation analysis" in the title or anywhere in the text. The search was conducted on $21 / 01 / 2020$. 


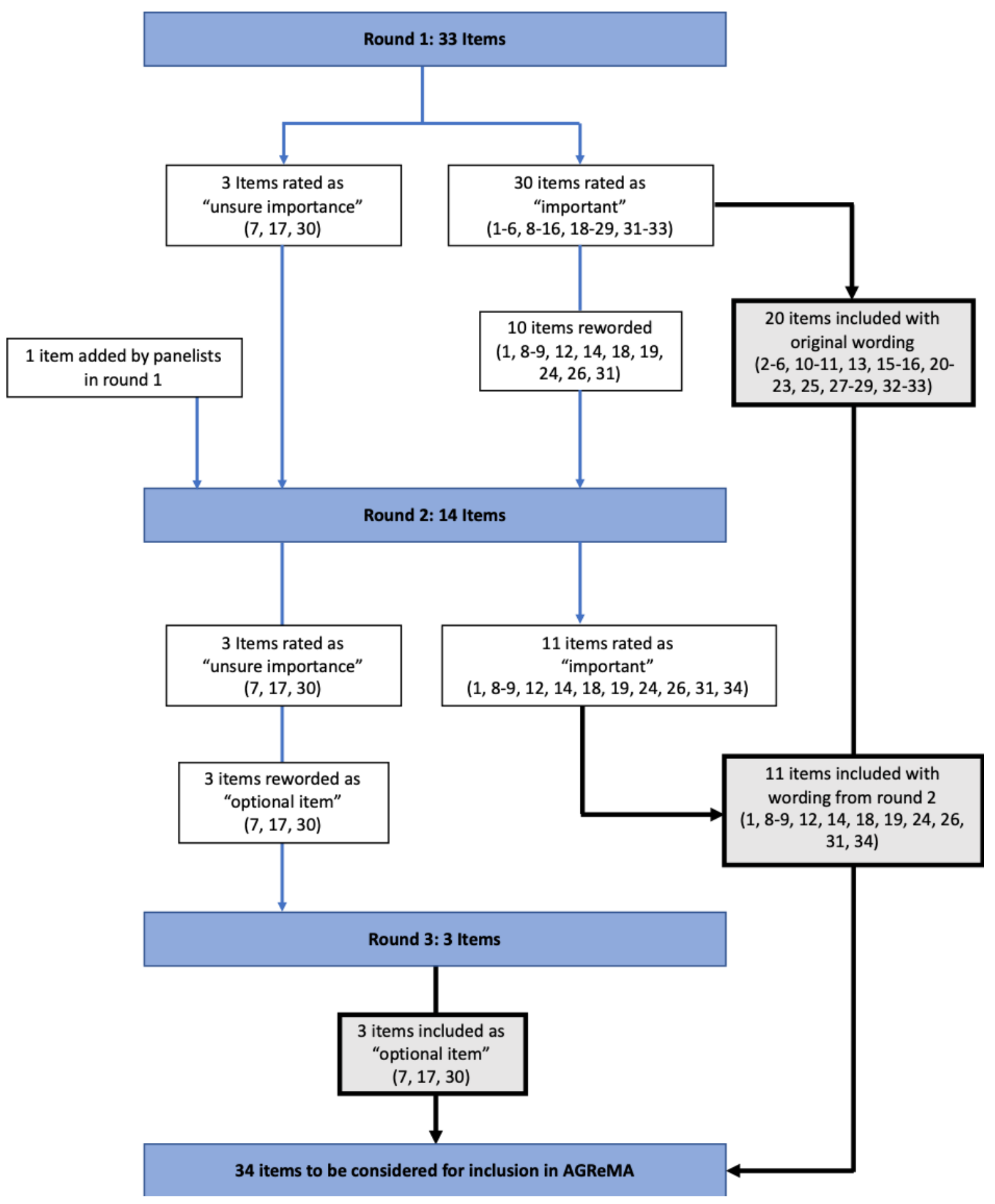

Figure 2. Flow of reporting items through the Delphi study 


\section{TABLES}

Table 1. Demographics of experts

\begin{tabular}{|c|c|}
\hline Characteristic & Number of Experts $(n=19)$ \\
\hline Age, mean (SD) & $45.5(8.7)$ \\
\hline Female, number $(\%)$ & $10(53 \%)$ \\
\hline Doctorate $(\mathrm{PhD})$ qualification, number (\%) & $19(100 \%)$ \\
\hline \multicolumn{2}{|l|}{ Country, number (\%) } \\
\hline USA & $8(42 \%)$ \\
\hline England/UK & $3(16 \%)$ \\
\hline Netherlands & $3(16 \%)$ \\
\hline Australia & $2(11 \%)$ \\
\hline Canada & $1(5 \%)$ \\
\hline Denmark & $1(5 \%)$ \\
\hline Belgium & $1(5 \%)$ \\
\hline \multicolumn{2}{|l|}{ Academic title, number (\%) } \\
\hline Assistant Professor & $8(42 \%)$ \\
\hline Professor & $7(37 \%)$ \\
\hline Researcher & $3(16 \%)$ \\
\hline Associate Professor & $1(5 \%)$ \\
\hline \multicolumn{2}{|l|}{ Primary job tile, number (\%) } \\
\hline Statistician & $6(32 \%)$ \\
\hline Epidemiologist & $5(26 \%)$ \\
\hline Clinical researcher & $2(11 \%)$ \\
\hline Health services researcher & $1(5 \%)$ \\
\hline Other & $5(26 \%)$ \\
\hline \multicolumn{2}{|c|}{ Role in development and/or application of mediation analysis, number (\%) } \\
\hline Application (applied mediation analysis) & $16(84 \%) \#$ \\
\hline $\begin{array}{l}\text { Synthesise (review and summarise studies that } \\
\text { apply mediation analysis) }\end{array}$ & $15(79 \%) \#$ \\
\hline Methodology (developed study designs) & $10(53 \%) \#$ \\
\hline Statistics (developed statistical methods) & $9(47 \%) \#$ \\
\hline Other & $1(5 \%) \#$ \\
\hline
\end{tabular}

\#Counts and percentages are not cumulative, panellists were able to select more than one option 
Table 2. Summary of ratings for each reporting item

\begin{tabular}{|c|c|c|c|c|c|c|c|c|}
\hline \multirow[b]{2}{*}{ Section } & \multirow[b]{2}{*}{$\begin{array}{l}\text { Item } \\
\text { number }\end{array}$} & \multirow[b]{2}{*}{ Final item description } & \multicolumn{2}{|c|}{ Round 1} & \multicolumn{2}{|c|}{ Round 2} & \multicolumn{2}{|c|}{ Round 3} \\
\hline & & & $\begin{array}{l}\text { Median } \\
\text { Importance } \\
\text { (IPR 30th - } \\
\text { 70th) }\end{array}$ & $\begin{array}{l}\text { Median } \\
\text { Confidence }\end{array}$ & $\begin{array}{l}\text { Median } \\
\text { Importance } \\
\text { (IPR 30th - } \\
\text { 70th) }\end{array}$ & $\begin{array}{l}\text { Median } \\
\text { Confidence }\end{array}$ & $\begin{array}{l}\text { Include as } \\
\text { optional } \\
\text { n }(\%)\end{array}$ & $\begin{array}{l}\text { Median } \\
\text { Confidence }\end{array}$ \\
\hline Title & 1 & $\begin{array}{l}\text { Identify the study as a mediation analysis or mechanism } \\
\text { evaluation* }\end{array}$ & $8(8-9)$ & 9 & $8(8-9)$ & 8 & $\begin{array}{l}\text { included fro } \\
\text { rated in roun }\end{array}$ & $\begin{array}{l}\text { round } 2 \text {, not } \\
3\end{array}$ \\
\hline \multirow[t]{7}{*}{ Introduction } & 2 & Specify the motivation for using mediation analysis & $8(7-9)$ & 9 & \multicolumn{4}{|c|}{ included from round 1 , not rated in rounds 2 and 3} \\
\hline & 3 & $\begin{array}{l}\text { An explanation for the biological/theoretical rationale for } \\
\text { studying the specified mechanism(s) }\end{array}$ & $8(7-9)$ & 9 & \multicolumn{4}{|c|}{ included from round 1 , not rated in rounds 2 and 3} \\
\hline & 4 & $\begin{array}{l}\text { Identify whether the proposed mediation analysis is } \\
\text { exploratory or confirmatory }\end{array}$ & $7(6-8)$ & 8 & \multicolumn{4}{|c|}{ included from round 1 , not rated in rounds 2 and 3} \\
\hline & 5 & State specific hypotheses for the mechanism(s) of interest & $8(7-9)$ & 8 & \multicolumn{4}{|c|}{ included from round 1 , not rated in rounds 2 and 3} \\
\hline & 6 & $\begin{array}{l}\text { Provide preliminary evidence or theoretical explanation for } \\
\text { why the intervention or exposure might cause change in the } \\
\text { proposed mediator(s) }\end{array}$ & $8(6-9)$ & 8 & \multicolumn{4}{|c|}{ included from round 1 , not rated in rounds 2 and 3} \\
\hline & 7 & $\begin{array}{l}\text { If applicable, provide reference(s) to any } \\
\text { protocols/preregistrations*\# }\end{array}$ & $6(5-7)$ & 8 & $6(5-6)$ & 7 & $18(95 \%)$ & 7 \\
\hline & 34 & $\begin{array}{l}\text { Provide preliminary evidence or theoretical explanation for } \\
\text { why there could be a relationship between the mediator(s) } \\
\text { and outcome(s) }\end{array}$ & - & - & $8(7-9)$ & 7 & $\begin{array}{l}\text { included fro } \\
\text { rated in roun }\end{array}$ & $\begin{array}{l}\text { round } 2 \text {, not } \\
3\end{array}$ \\
\hline \multirow[t]{3}{*}{ Methods } & 8 & $\begin{array}{l}\text { Describe how the study design features allow for estimating } \\
\text { indirect or direct effects* }\end{array}$ & $9(8-9)$ & 9 & $9(8-9)$ & 9 & $\begin{array}{l}\text { included fro } \\
\text { rated in roun }\end{array}$ & $\begin{array}{l}\text { round } 2 \text {, not } \\
3\end{array}$ \\
\hline & 9 & $\begin{array}{l}\text { A clear specification of the main effect(s) of interest } \\
\text { (indirect effect and/or direct effect)* }\end{array}$ & $8(7-9)$ & 8 & $8(7-8)$ & 8 & $\begin{array}{l}\text { included fro } \\
\text { rated in roun }\end{array}$ & $\begin{array}{l}\text { round } 2 \text {, not } \\
3\end{array}$ \\
\hline & 10 & $\begin{array}{l}\text { Include a graphical representation of the model(s) being } \\
\text { tested (e.g. directed acyclic graph, structural equation } \\
\text { model) }\end{array}$ & $7(7-9)$ & 8 & \multicolumn{4}{|c|}{ included from round 1 , not rated in rounds 2 and 3} \\
\hline
\end{tabular}




\begin{tabular}{|c|c|c|c|c|c|c|c|}
\hline 11 & $\begin{array}{l}\text { Report possible confounders in the specified mediation } \\
\text { model how they were measured and adjusted }\end{array}$ & $8(8-9)$ & 8 & \multicolumn{4}{|c|}{ included from round 1 , not rated in rounds 2 and 3} \\
\hline 12 & $\begin{array}{l}\text { Describe how possible interactions in the specified } \\
\text { mediation model (e.g. exposure-mediator interaction) were } \\
\text { handled in the analysis* }\end{array}$ & $7(7-8)$ & 8 & $7(7-8)$ & 8 & \multicolumn{2}{|c|}{$\begin{array}{l}\text { included from round } 2 \text {, not } \\
\text { rated in round } 3\end{array}$} \\
\hline 13 & $\begin{array}{l}\text { If relevant, specify the multilevel nature of the exposure, } \\
\text { mediator, and outcome (e.g. exposure and mediator at group } \\
\text { level, and outcome at individual level) }\end{array}$ & $8(8-9)$ & 8 & \multicolumn{4}{|c|}{ included from round 1 , not rated in rounds 2 and 3} \\
\hline 14 & $\begin{array}{l}\text { Outline the causal assumptions that were made (e.g., no } \\
\text { unmeasured confounding)* }\end{array}$ & $8(7-8)$ & 8 & $8(8-8)$ & 8 & \multicolumn{2}{|c|}{$\begin{array}{l}\text { included from round } 2 \text {, not } \\
\text { rated in round } 3\end{array}$} \\
\hline 15 & $\begin{array}{l}\text { State how the exposure, mediator and outcome } \\
\text { variables were defined and measured }\end{array}$ & $9(9-9)$ & 9 & \multicolumn{4}{|c|}{ included from round 1 , not rated in rounds 2 and 3} \\
\hline 16 & $\begin{array}{l}\text { State when the exposure, mediator and outcome variables } \\
\text { were measured }\end{array}$ & $9(9-9)$ & 9 & \multicolumn{4}{|c|}{ included from round 1 , not rated in rounds 2 and 3} \\
\hline 17 & $\begin{array}{l}\text { If the mediation analysis was preplanned, describe } \\
\text { how sample size was determined*\# }\end{array}$ & $6(5-7)$ & 8 & $6(5-7)$ & 7 & $16(85 \%)$ & 7 \\
\hline 18 & $\begin{array}{l}\text { Specify criteria or statistical tests used to assess mediation, } \\
\text { with references* }\end{array}$ & $8(7-9)$ & 9 & $8(7-9)$ & 8 & $\begin{array}{l}\text { included } \mathrm{f} \\
\text { rated in } \mathrm{rc}\end{array}$ & round 2 , not \\
\hline 19 & $\begin{array}{l}\text { Describe statistical models used for the mediator(s) and } \\
\text { outcome(s) - i.e., the functional form* }\end{array}$ & $8(8-9)$ & 8 & $8(8-9)$ & 8 & $\begin{array}{l}\text { included } \mathrm{f} \\
\text { rated in ro }\end{array}$ & round 2 , not \\
\hline 20 & $\begin{array}{l}\text { State whether interaction between exposure and mediator } \\
\text { was considered, and how they were modelled }\end{array}$ & $7(7-8)$ & 8 & \multicolumn{4}{|c|}{ included from round 1 , not rated in rounds 2 and 3} \\
\hline 21 & $\begin{array}{l}\text { If relevant for exposure, mediator, and outcome being } \\
\text { considered, state how the following were addressed: } \\
\text { - clustering or repeated events - competing risks }\end{array}$ & $7(7-9)$ & 7 & \multicolumn{4}{|c|}{ included from round 1 , not rated in rounds 2 and 3} \\
\hline 22 & $\begin{array}{l}\text { If there was missing data, describe how much was missing } \\
\text { for the mediator(s) and outcome(s), and provide an } \\
\text { explanation of how missing data was handled in the analysis }\end{array}$ & $8(7-9)$ & 9 & \multicolumn{4}{|c|}{ included from round 1 , not rated in rounds 2 and 3} \\
\hline 23 & $\begin{array}{l}\text { Describe the method used to adjust for measured } \\
\text { confounders of the exposure-mediator, exposure-outcome, } \\
\text { mediator-outcome effects }\end{array}$ & $8(7-9)$ & 9 & \multicolumn{4}{|c|}{ included from round 1 , not rated in rounds 2 and 3} \\
\hline 24 & $\begin{array}{l}\text { If sensitivity analysis was used, provide a reference to the } \\
\text { method* }\end{array}$ & $7(7-9)$ & 8 & $8(7-8)$ & 8 & \multicolumn{2}{|c|}{$\begin{array}{l}\text { included from round } 2 \text {, not } \\
\text { rated in round } 3\end{array}$} \\
\hline
\end{tabular}




\begin{tabular}{|c|c|c|c|c|c|c|c|c|}
\hline \multirow{5}{*}{ Results } & 25 & \multirow{2}{*}{$\begin{array}{l}\text { Provide references to statistical software and packages used } \\
\text { Report any changes to the selected mediator or statistical } \\
\text { model(s) after the study commenced, with reasons* }\end{array}$} & \multirow{2}{*}{$\begin{array}{l}8(7-9) \\
7(6-9)\end{array}$} & \multirow{2}{*}{$\begin{array}{l}9 \\
8\end{array}$} & \multicolumn{4}{|c|}{ included from round 1 , not rated in rounds 2 and 3} \\
\hline & 26 & & & & $7(6-7)$ & 7 & $\begin{array}{l}\text { included } \mathrm{f} \\
\text { rated in ro }\end{array}$ & $\begin{array}{l}\text { round } 2 \text {, not } \\
3\end{array}$ \\
\hline & 27 & $\begin{array}{l}\text { Unstandardized or standardized effects and precision } \\
\text { estimates for the total, direct, and indirect effects }\end{array}$ & $9(8-9)$ & 9 & \multicolumn{4}{|c|}{ included from round 1 , not rated in rounds 2 and 3} \\
\hline & 28 & $\begin{array}{l}\text { Unstandardized or standardized effects and precision } \\
\text { estimates for the exposure-mediator effect }\end{array}$ & $8(7-9)$ & 8 & \multicolumn{4}{|c|}{ included from round 1 , not rated in rounds 2 and 3} \\
\hline & 29 & $\begin{array}{l}\text { Unstandardized or standardized effects and precision } \\
\text { estimates for the mediator-outcome effect }\end{array}$ & $8(7-9)$ & 8 & \multicolumn{4}{|c|}{ included from round 1 , not rated in rounds 2 and 3} \\
\hline & 30 & $\begin{array}{l}\text { If applicable, report the proportion mediated or } \\
\text { eliminated with precision estimates*\# }\end{array}$ & $6(5-7)$ & 7 & $6(5-6)$ & 7 & $14(74 \%)$ & 7 \\
\hline & 31 & $\begin{array}{l}\text { Results from any sensitivity analysis (for example, the level } \\
\text { of unmeasured confounding that would invalidate the effect } \\
\text { of interest)* }\end{array}$ & $7(6-8)$ & 8 & $7(6-8)$ & 8 & $\begin{array}{l}\text { included } \mathrm{f} \\
\text { rated in ro }\end{array}$ & round 2 , not \\
\hline \multirow[t]{2}{*}{ Discussion } & 32 & $\begin{array}{l}\text { Discuss limitations of the study, including sources of } \\
\text { potential bias (e.g. residual confounding, statistical } \\
\text { uncertainty, measurement error, and generalisability) }\end{array}$ & $9(8-9)$ & 9 & \multicolumn{4}{|c|}{ included from round 1 , not rated in rounds 2 and 3} \\
\hline & 33 & $\begin{array}{l}\text { Implications of results considering the primary objectives, } \\
\text { main findings, limitations, and results from relevant studies }\end{array}$ & $9(9-9)$ & 9 & \multicolumn{4}{|c|}{ included from round 1 , not rated in rounds 2 and 3} \\
\hline
\end{tabular}

* item reworded from round 1 qualitative comments

\# item reworded from round 2 qualitative comments

IPR, Inter-percentile range 
APPENDIX Table 1. Qualitative comments provided by panellists in each Delphi round

\begin{tabular}{|c|c|c|c|c|c|}
\hline Section & Item \# & Item Description & Qualitative Comments & Qualitative Comments & Qualitative Comments \\
\hline & & & Round 1 & Round 2 & Round 3 \\
\hline Title & 1 & $\begin{array}{l}\text { Identify the study as a mediation analysis or } \\
\text { mechanism evaluation }\end{array}$ & $\begin{array}{l}\text { 1) "I found this question to be a bit unclear and } \\
\text { ambiguous as the word 'identification' can have } \\
\text { various meanings in this context." }\end{array}$ & & \\
\hline \multirow[t]{21}{*}{ Introduction } & & & 2) "It very much depends on context" & & \\
\hline & & & 3) "There are two aspects of theory for & & \\
\hline & & & mediation, theory for how an intervention will & & \\
\hline & & & change the mediator and theory for how the & & \\
\hline & & & $\begin{array}{l}\text { mediator is related to the outcome. Both are } \\
\text { important The guestions so far conflate these }\end{array}$ & & \\
\hline & & & $\begin{array}{l}\text { two different aspects of mediation - see for } \\
\text { example. MacKinnon } 2008 \text { Chanter } 2 "\end{array}$ & & \\
\hline & 2 & $\begin{array}{l}\text { Specify the motivation for using mediation } \\
\text { analysis }\end{array}$ & $\begin{array}{l}\text { 4) "I felt this was less important as the answer to } \\
\text { this should be clear from the other questions?" }\end{array}$ & & \\
\hline & 3 & $\begin{array}{l}\text { An explanation for the biological/theoretical } \\
\text { rationale for studying the specified mechanism(s) }\end{array}$ & & & \\
\hline & 4 & $\begin{array}{l}\text { Identify whether the proposed mediation analysis } \\
\text { is exploratory or confirmatory }\end{array}$ & & & \\
\hline & 5 & $\begin{array}{l}\text { State specific hypotheses for the mechanism(s) of } \\
\text { interest }\end{array}$ & & & \\
\hline & 6 & $\begin{array}{l}\text { Provide preliminary evidence or theoretical } \\
\text { explanation for why the intervention or exposure } \\
\text { might cause change in the proposed mediator(s) }\end{array}$ & $\begin{array}{l}\text { 5) "Identification and rationale for the potential } \\
\text { mediators is crucial. If we cannot provide why } \\
\text { we are testing mediator pathways, there is little } \\
\text { use performing the analysis." }\end{array}$ & & \\
\hline & 34 & Provide preliminary evidence or theoretical & & 1) "This is the crux of doing these analyses. A & \\
\hline & & explanation for why there could be a relationship & & must!"” & \\
\hline & & between the mediator(s) and outcome(s) & & $\begin{array}{l}\text { 2) Medration analysis is always causal and } \\
\text { hence a justification of one's assumption in }\end{array}$ & \\
\hline & & & & $\begin{array}{l}\text { pursuing it should be given" } \\
\text { 3) "Not sure that researchers have to be told to do }\end{array}$ & \\
\hline & & & & this, and post hoc reasoning cannot be prevented & \\
\hline & & & & by rules, but it is something that should be done & \\
\hline & & & & $\begin{array}{l}\text { betore running the analysis." } \\
\text { 4) "I think this depends partly on the sort of }\end{array}$ & \\
\hline & & & & study/what stage the science is at, i.e. earlier & \\
\hline & & & & phase versus confirmatory. If this was a & \\
\hline & & & & requirement, it might make doing hypothesis & \\
\hline
\end{tabular}


If applicable, provide reference(s) to any

protocols/preregistrations

Methods

Describe how the study design features allow for estimating indirect or direct effects

A clear specification of the main effect(s) of interest (indirect effect and/or direct effect)

Include a graphical representation of the model(s) being tested (e.g. directed acyclic graph, structural equation model)

Report possible confounders in the specified

mediation model how they were measured and adjusted

12 Describe how possible interactions in the specified mediation model (e.g. exposuremediator interaction) were handled in the analysis generating studies difficult. And I don't see why

it would just apply to mediator outcome and not

also "independent variable" or "treatment" and

mediator. It is important to provide if it exists - it

would make any publication more robust."

6) "I am not sure exactly what you mean"

7) "Some of these questions concern overlapping

topics, so I would simplify them to focus on:

a) what is the target of estimation (again please

less focus on testing)

b) what estimation method was adopted and

consequently which assumptions were invoked to

interpret the estimates as mediation effects

Point b) will encompass:

(i) the modelling of confounders

(ii) the specific model assumptions (eg

independent errors vs clustering; $\mathrm{PH}$ assumption)

(iii) the parametric specification of the models

involved (eg inclusion of non-linearities,

interactions, etc)"

8) "I would expand the statement to include

estimation, and to reduce the focus on testing"

9) "Language differs across disciplines and term such as natural indirect effect, natural direct effect, controlled direct effect will not be familiar

"I found the original wording of 9 examples more compelling. Same for 14"
10) "The question on interactions seems a bit primitive. The key is not interaction, but model fit. Interactions is just one aspect of this. The designers of the Delphi review process should read up on most recent methods" 
13 If relevant, specify the multilevel nature of the exposure, mediator, and outcome (e.g. exposure and mediator at group level, and outcome at individual level)

14

Outline the causal assumptions that were made

(e.g., no unmeasured confounding)

State when the exposure, mediator and outcome

variables were measured

17 If the mediation analysis was preplanned,

describe how sample size was determined

12) "I find it less important to discuss

consistency, but crucially important to discuss exchangeability and positivity."

13) "I think stating the assumptions are critical

but I would give priority to the

exchangeability/no-unmeasured-confounding assumptions over consistency, interactions, positivity. I also think how the assumptions are stated will vary according to the journal. An

Epidemiology journal may be happy to see all the technical assumptions. This is NOT the case with clinical journals. With clinical journals I think it

is best just to state "The methods assume that

baseline covariates control for exposure-

outcome-, mediator-outcome-, and exposuremediator confounding and leave it at that.

Likewise, when stating the effect of interest, I

think it is good to specify "natural" vs.

"controlled" in an epidemiology journal, but I

think this is confusing in clinical journals. There

I think it is best just to refer to "direct and

indirect effects" (if effect decomposition / natura effects are of interest) and to just refer to a

"direct effect" (if the controlled direct effect is of interest). Always give references to more

technical work but do not necessarily include

these technicalities in the methods section itself of a clinical journal"

14) "I don't think current sample size calculation mediation analysis, and therefore don't think they
5) "I found the original wording of 9 examples more compelling. Same for 14 "
1) "I agree with the comments."

2) "I agree that sample size is context specific and it is often not useful (small samples etc). However, mediation analysis does require larger 
should be enforced or that a sample size

calculation is necessarily indicative of a better

quality study."

15) "Power calculation and sample size

generation should relate to mediation analysis (not original primary outcome - as is often the case)"

16) "Again depends on context. The size of

observational studies is often not controllable, eg those derived from linkage across electronic

health records, hence reporting of assumptions

underlying power calculations are not sensible for all studies."

17) "This depends on the setting and if mediation was a primary aim. I think it is important to

acknowledge that power to detect indirect effects is often greater than total effects, but power to detect direct effects is often less than total effects."

18) "Many times these types of studies are secondary analyses of existing data from an observational study."

18 Specify criteria or statistical tests used to assess mediation, with references

19 Describe statistical models used for the

mediator(s) and outcome(s) - i.e., the functiona form

State whether interaction between exposure an mediator was considered, and how they were modelled

21 If relevant for exposure, mediator, and outcome being considered, state how the following were addressed:

- clustering or repeated events - competing risks

19) "Not sure the second sentence is necessary?

The wording of the sentence is confusing

(particularly "estimate exact values")"

20) "Would suggest separating "Describe

statistical models used for the mediator(s) and

outcome(s) (the functional form) " from "any

assumptions underlying use of such models" -

make this two separate criteria. The first point is

critical - must describe the models used - the

second part is important but not as critical as the

first, in my opinion."

21) "Again seems [the] interaction question

illustrates lack of current knowledge. Other

questions are just generic. They apply to any data

analysis so..... what's the point here?" numbers (or acknowledgement of bootstrapping etc) so I think it is important to at least acknowledge...."

3) "It may not apply to many, and it almost seems like punishment for planning. How about reporting power to detect important effects instead"

4) "Although this will often not be the case, I 
and provide an explanation of how missing data

was handled in the analysis

Describe the method used to adjust for measure confounders of the exposure-mediator, exposureoutcome, mediator-outcome effects

24 If sensitivity analysis was used, provide a

reference to the method

25 Provide references to statistical software and

packages used

Results

Report any changes to the selected mediator or statistical model(s) after the study commenced, with reasons

Unstandardized or standardized effects an precision estimates for the total, direct, and indirect effects

28 Unstandardized or standardized effects and precision estimates for the exposure-mediato effect

29 Unstandardized or standardized effects and precision estimates for the mediator-outcome effect

If applicable, report the proportion mediated or eliminated with precision estimates\#
22) "With sensitivity analysis I think it is fine just to provide the references on the approach used, rather than describe the approach itself."

23) "Regarding the changes to hypothesized mediators... I think as our fields evolve and we learn about new potential mechanisms or treatment targets, new mediators may be

hypothesized for existing treatment outcomes data. Requiring everything be known from the outset of a study (ie, proposal phase), when treatment trials last years, would be overly confining and would likely restrict progress and potential innovation."

24) "I did not understand what was meant with this statement"

25) "Not sure what you mean with

"Unstandardized/standardized": does that mean marginal or conditional (on confounders)?'

26) "Proportion mediated is unstable unless sample size is large - See MacKinnon et al, 1995 Multivariate Behavioral Research and Miocevic et al., 2015 Behavior Research Methods. There are better effect size measures. But overall I agree it would be wonderful if everyone reported the same effect size measures even in the proportion is unstable unless effect sizes and/or sample sizes are large."

6) "I do think it's important to report any changes, especially if this takes into account new findings published since the protocol was published. I think this helps strengthen any heoretical underpinnings to the planned mediation analysis."

7) "Perhaps I am misunderstanding the concep "after the study commenced." A controlled trial may not have initially aimed to uncover mechanisms, but if the "study" means a subsequent post hoc mediation analysis itself, then yes, changes would need to be reported."

8) "Not every mediation analysis will lead to ocus on proportion mediated, so the guideline mediated is part of the study aims"

10) "I see where raters are coming from in term of common reporting metrics and requiring precision estimates, but I agree with the state problems. If by precision estimates the

presentation of CI's is implied, it likely needs to be acknowledged that these may not be bounded by 0 and 100 (probably related to the final rater
5) "There are many proposed effect sizes for mediation analysis, and all have weaknesses. The guidelines should not implicitly favour one (and one with such major problems noted in the literature) over the others until the literature can agree on one or two superior effect size measures."

6) "Not always the point of the paper!"

7) "Agree with the comments above - proportion mediated is not the most accurate way to present results." 
27) "I would say the issue is that they should report effects or proportion mediated, with precision estimates. I think the precision estimates is the key part so perhaps a point about "including precision estimates on indirect effect or proportion mediated" should be presented separately."

Results from any sensitivity analysis (fo example, the level of unmeasured confounding that would invalidate the effect of interest)

Discussion $\quad 32 \quad$ Discuss limitations of the study, including

sources of potential bias (e.g. residual

confounding, statistical uncertainty, measurement error, and generalisability)

33 Implications of results considering the primary

objectives, main findings, limitations, and results

from relevant studies

General Comments (measured or unmeasured) needs to be discussed.

31) "There could be more about the measuremen

of the mediators as well, e.g., whether the mediator is a biological measure, weight, or a sensitivity analysis"', the data prior to analysis and report the

standardised estimates and $\mathrm{Cl}^{\prime}$ arising from this data, with the point estimate only of the

proportion mediated (for continuous mediator

and outcome) as it is. I agree it would be good to suggest some sort of standard way of reporting, might standardised estimates be one way? I think it is difficult as there are different ways to standardise and a number of different effect sizes that could be chosen. Then there is the issue of hon-contingus outcos. I haven't worked with hese so far so haven't fully thought this through, these so far so haven't fully thought his through, but does proportion mediated make sense for non-continuous outcomes?"

11) "I think either a measure of the indirect effect OR the proportion mediated is needed. And whichever is provided, it needs to be accompanied by confidence intervals or other measure of precision."

8) "I think it is more important to report the indirect effect and CIs as the CIs for the proportion mediated are a bit odd/possibly not informative. Reporting the indirect effect and Cls should be mandatory, reporting the proportion mediated optional."

9) "I disagree with removing from guidelines or including as optional. Some form of precision estimate must be included The phrasing should be changed to be changed to indicate that pecision estimate is the proportion mediated." Ge

(1)

30) "None of the questions seems to address the question of no-exposure dep confounding. Also known as no-intertwined causal pathways. This should have been included. Also other mediators And the likely causal links between these mediators."

28) "I don't think that sensitivity analysis is a $\quad 12$ ) "Sensitivity analysis is important, but I do not label it as critical because the involved parameters can be very difficult to choose, and the available sensitivity analyses can only be applied in very simple mediation analyses. This makes it difficult to strive towards enforcing it Likewise, sensitivity analyses are not routinely considered in observational analyses of total effects because they can be overly complicated."

General comments in relation to items 7, 17, 30: 13) "I agree with the points mentioned. I am in doubt as to what you actually ask in this round." 14) "If these items were not REQUIRED (because of all the concerns listed) - optional would be ok." only feasible in very simple settings, so I don't
ons think they should be imposed. Proportion mediated is usually very imprecise so I don't 
psychological measure such as self-efficacy, or

individual perception of a social norm,

environmental measure such as perceptions that

the person is being rated by experimenters, etc.

There are substantial differences in the ease of

changing a mediator with an intervention - some

intervention components may change a mediator

quickly but others may be much more difficult to

change. For many studies, the intervention is

encouragement to do something, not actually

changing the mediator.'

32) "I would recommend the inclusion of a table

describing how intervention or treatment was

designed to influence potential mediators.

Ideally, this should include behaviour change

strategies etc."

33 "I think some of your entries are not specific

to mediation analysis but general for any

scientific papers - so not sure if you should

develop guidelines that are more specific to this

area, instead of revisiting gold standard of

scientific reporting (eg discussing limitations and potential biases)"

34) "I think reporting guidelines also need to take

into account whether the entire paper is on

mediation, or whether this is just a secondary

analysis with the primary analysis (in the same

paper) being the analysis of total effects. If the

mediation analysis is a secondary part of the

paper then obviously a lot less detail can be

included."

35) "The number of mediation analyses

conducted, if not all reported"

36) "Thank you for the opportunity to participate.

Some of these were difficult to answer, because

they might not be applicable, or because there

were several questions included within one

question."

37) "This is great!" 